\title{
THE PRACTICE OF CAREER DEVELOPMENT IN THE INTERNATIONAL HUMAN RESOURCE MANAGEMENT OF THE EUROPEAN COUNTRIES
}

\author{
UDC: 005.966(4) \\ Original Scientific Paper \\ Nemanja BERBER ${ }^{1}$, Agneš SLAVIĆ ${ }^{2}$ \\ ${ }^{1}$ University of Novi Sad, Faculty of Economics, 24000 Subotica, Segedinski put 9-1,1 Republic of Serbia \\ E-mail: berber@ef.uns.ac.rs \\ ${ }^{2}$ University of Novi Sad, Faculty of Economics, 24000 Subotica, Segedinski put 9-1,1 Republic of Serbia
}

Paper received: 05.05.2014.; Paper accepted: 21.05.2014.

\begin{abstract}
The function very close to the training in the management of human resources is certainly the human resource development. Specifically, the employees acquire new knowledge, abilities and skills during the training process, but also gain new experiences through various business tasks during their working life, developing themselves both, in private life and in the professional sense. Human resource development is seen as the development of the expertise of people through organizational development and training of employees in order of improvement of the performances. In this paper authors explored the practice of carrier development in European countries. Research was based on data from international project, CRANET, in the period from 2008 to 2010. The authors presented data about the usage of techniques for evaluation of career development and investigated obtained results.
\end{abstract}

Key words: human resource management, development, career, CRANET, Europe.

\section{INTRODUCTION}

Human resource management is one of the most important management functions, but also one process which includes several interrelated activities (job design, job analysis, HR planning, staffing, training and development, compensation and benefits, industrial relation, and retention). It has a great impact on the effectiveness and efficiency of contemporary organizations, and it is usually in the function of competitive advantage (Campbell et al., 2012; Berber, 2011; Wright and McMahan, 2011; Progoulaki and Theotokas, 2010; Lado and Wilson, 1994; Schuler and MacMillan, 1984). Bearing in mind that HRM has a positive impact on organizational performances, for the purpose of this paper authors decided to explore one often mentioned HRM activity, related to the learning and acquiring new knowledge and experiences - the human resource development (HRD). HRD is seen as the development of the expertise of people through organizational development and training of employees in order of improvement of the performances (Swanson,
1995). Career refers to the employment, movement between jobs, position, level of responsibility and challenges. Career can be seen as keeping one's position inside job, mobility within the organization, or the characteristics of the employee. Each career includes different jobs, positions, and experience. The most appropriate observation of career is that it is "unlimited" and that could include moving through several different jobs or occupations (Leković and Šušnjar, 2010). HRD becomes even more interesting if the international context is in question - with all the challenges related to the cultural, economic and social differences between organizations from different countries.

The subject of the research in this paper was the practice of career development in European countries.The research was based on data from international project CRANET in the period from 2008 to 2010 . The authors presented data about the usage of techniques for evaluation of career development in organizations from 25 countries 
from Europe (EU and non-EU countries) and investigated results.

\section{THEORETICAL BACKGROUND}

According to Grubić-Nešić (2005) career can be described as a set of job roles of individuals, or move up and progress in work roles. Career is individually perceived order of the attitudes and behaviors associated with the experience and activities related to the operation during a person's life and career are changes in values, attitudes, and motivation that occur as a person becomes older. Career can be defined wider as the development of individual in learning and work throughout their lives.

If we look at the career development in an international context, it is important to pay attention to the role of international tasks to staff development. The international engagements have been known as an important mechanism for the development of international expertise. The expected outputs of the engagement include:

- Development of management, since individuals acquire international expertise that helps in the advancement of his/her career, while multinationals gain available international executives with experiences, from which some of them will be extracted for the international engagements.

- Organizational development, since international assignments provide accumulated knowledge, skills and abilities for multinational companies. Global mindset is an important advantage because it expands the horizons of individuals. Furthermore, foreign managers are agents of direct control and socialization that help to transfer the knowledge and skills (Dowling et al., 2008).

In the book Global careers in 2011 authors Dickmann and Baruch indicated the expatriation process and cyclical global career. According to their understanding the individual expatriation certainly is a small career cycle, in accordance with the general development of the career stages foundation (starting a career in elementary education during adolescence), the entry, advancement, re- assessment and evaluation, enhance existing career or return to the stage learning, the decline and withdrawal (pension) (Baruch, 2004). If we look at global career, we can see similar phases or stages. First, an expatriate with his family appears in the new situation (home and business task) after training and preparation - which corresponds to the stage of establishment, the beginning of his career. The first period of global careers, called the honeymoon period, is similar to the stage of the entrance, because he/she learns about new environment, policy, culture and regulations. After this, there is a stage of performance development, when expatriates progresses from the viewpoint of performance, learning and experience. The next stage is the reevaluation, in which expatriate assess its effects and results of the work and the possible adoption of a decision on early returns, staying on task, or enhancing an existing career. At the same time immigrants make decisions regarding new environment, where they operate, to make that environment as their permanent residence. Stages of decline and withdrawal are recognized when the expatriate reduces the level of actual performance or is already thinking about a new task in the home country, or if they decide to leave the organization after repatriation.

Global career management is about managing people's career across borders, and there are two major challenges. "First, how to manage career in multinational corporations where there are diverse operations in different countries and the system needs adjustment, understanding, and variety, while keeping to certain general strategy. The second is concerned mostly with the management of expatriation and repatriation although many are involved in global work even if never leaving their own country-for example, their career could be global or internationalized just because many work on teams that span many different countries and cultures. It is not merely the physical movement from country to country but the psychological aspects of working and adjusting to others from other cultures and seeing this boundarylessness of having colleagues, customers, partnerships, etc. around the world" (Baruch, 2006, p. 133).

One very interesting issue in HRD are the methods of career management. Namely, there are many methods that organizations can use for the purpose of the career development of their employees. Mayrhofer et al. (2004) explored the usage of several HRD methods: formal career planning, succession planning, job rotation, and high-flier schemes. With the exception of succession planning and high-flier schemes in the UK, where a slight decrease can be observed, all the other countries and practices showed an increase in the usage of these instruments. The authors explained the results in two ways. Firstly, organizations at least create the impression that they are on top of 
developments. Secondly, they most likely contribute to developing employees in a way that they truly become able to better cope with career and environmental demands. In one similar research in Ireland, authors Heraty and Morley (2000) explored the usage of formal career plans, assessment centers, succession plans, planned job rotation, high flier schemes, and international experience schemes as methods for career development. They found that succession plans, planned job rotations and formal career plans are favored most by respondents, while assessment centers are utilized by only a very small minority of organizations, since they are usually very expensive. Papalexandris and Panayotopoulou (2004) explored the relations between HRM and cultural differences. Career development methods seem to be more influenced by the cultural context. Namely, there was detected a positive relationship between power distance and the use of formal career plans, as well as assertiveness and the use of succession plans. On the other hand, there was a negative relationship between uncertainty avoidance and the use of both career and succession plans and strong negative relations between humane orientation, collectivism and the use of career and succession plans.

\section{METHODOLOGY}

In the present research the authors used data obtained during the CRANET research, in the period 2008-2010. This international organization organizes comparative researches on the policies and practices of human resource management, using a standardized questionnaire. The survey is undertaken approximately every four years with the purpose to provide high quality data for academics, public and private sector organizations, as well as HRM students, and to create new knowledge about human resource management practice in different countries of the world. The questionnaires are filled out by the HRM executives of companies with more than 50 employees. The Cranet questionnaire is divided into six sections (Parry et al., 2013): HRM activity in the organization, staffing practices, employee development, compensation and benefits, employee relations and communication, and organizational details. For the purpose of the research the authors decided to explore section III, where respondents were asked to mark the level of the usage of different methods of career development.

Variables used in the research were:

- Special tasks/projects to stimulate learning/on the job training $(\mathrm{m} 1)$

- Involvement in cross-organizational / disciplinary/ functional tasks ( $\mathrm{m} 2)$

- Participation in project team work (m3)

- Networking (m4)

- Formal career plans (m5)

- Development centers (m6)

- Succession plans (m7)

- Planned job rotation (m8)

- "High flier" schemes (m9)

- Experience schemes (internal movement to another department, whether in the same country or abroad) (m10)

- Secondments to other organisations (external movement to another organization for a temporary period of time) (m11)

- Coaching (m12)

- Mentoring (m13)

- Computer based packages/e-learning (m14)

Grades for the usage of the presented methods were given in the form of Likert scale, where $0=$ not at all and $4=$ to a very great extent.

Table 1 shows the sample used in the research. The authors explored data for 25 countries from Europe. The biggest shares of companies are from private $(67.8 \%)$ and public (17.1\%) sector, while the mixed private-public and not for profit sector were in smaller percentage $(2.7 \%$ and $4 \%$, respectively).

\section{RESULTS AND DISSCUSION}

The level of the usage of the methods for career development is presented in table 2 . 
Table 1: Sample of organizations from Europe

\begin{tabular}{|l|c|c|c|}
\hline Country & $\begin{array}{c}\text { Number of } \\
\text { organizations }\end{array}$ & \% & $\begin{array}{c}\text { Cumulative } \\
\text { \% }\end{array}$ \\
\hline Austria & 203 & 4.8 & 4.8 \\
\hline Belgium & 240 & 5.7 & 10.5 \\
\hline Bulgaria & 267 & 6.3 & 16.8 \\
\hline Cyprus & 90 & 2.1 & 18.9 \\
\hline Czech Republic & 54 & 1.3 & 20.2 \\
\hline Denmark & 362 & 8.5 & 28.7 \\
\hline Estonia & 74 & 1.7 & 30.5 \\
\hline Finland & 136 & 3.2 & 33.7 \\
\hline France & 157 & 3.7 & 37.4 \\
\hline Germany & 420 & 9.9 & 47.3 \\
\hline Greece & 214 & 5.1 & 52.3 \\
\hline Hungary & 139 & 3.3 & 55.6 \\
\hline Ireland & 103 & 2.4 & 58.1 \\
\hline Italia & 157 & 3.7 & 61.8 \\
\hline Lithuania & 119 & 2.8 & 64.6 \\
\hline Netherlands & 116 & 2.7 & 67.3 \\
\hline Slovakia & 225 & 5.3 & 72.6 \\
\hline Slovenia & 219 & 5.2 & 77.8 \\
\hline Sweden & 282 & 6.7 & 84.4 \\
\hline UK & 218 & 5.1 & 89.6 \\
\hline Island & 138 & 3.3 & 92.8 \\
\hline Norway & 98 & 2.3 & 95.2 \\
\hline Russia & 56 & 1.3 & 96.5 \\
\hline Serbia & 50 & 1.2 & 97.7 \\
\hline Switzerland & $\mathbf{4 2 3 6}$ & $\mathbf{1 0 0 . 0}$ & 100.0 \\
\hline Total & 2.3 & \\
\hline Source: Authord & & \\
\hline
\end{tabular}

Source: Authors research on the basis of CRANET data

Table 2: The level of the usage of the different methods for career development in organizations from

\begin{tabular}{|c|c|c|c|c|c|c|c|c|c|c|c|c|c|c|}
\hline \multicolumn{15}{|c|}{ Europe } \\
\hline State & m1 & m2 & $\mathbf{m 3}$ & $\mathrm{m} 4$ & m5 & m6 & m7 & m8 & m9 & m10 & m11 & m12 & m13 & m14 \\
\hline Aus & 2.03 & 1.97 & 2.48 & 1.55 & .90 & .72 & 1.65 & .82 & 1.10 & 1.18 & .58 & 1.42 & 1.19 & .86 \\
\hline $\mathrm{Bel}$ & 13 & 1.87 & 2.27 & 1.53 & 1.39 & 1.25 & 1.36 & 1.21 & & 1.85 & & & & 1.26 \\
\hline Bug & .84 & .44 & .87 & .66 & .39 & & .40 & .35 & .30 & .53 & .36 & .70 & .31 & .40 \\
\hline Cyp & 2.40 & 1.82 & 2.03 & 1.16 & 1.00 & .53 & .84 & 1.45 & .89 & 1.50 & .62 & 2.24 & 2.06 & 1.43 \\
\hline Czch & .96 & 1.98 & 2.28 & .88 & 1.49 & .59 & 1.27 & .84 & .91 & 1.58 & 1.04 & .95 & .84 & 1.09 \\
\hline Den & .25 & 1.39 & 1.51 & 1.02 & .88 & .24 & .56 & .48 & .43 & .94 & .24 & 1.20 & .85 & .90 \\
\hline Est & 94 & 1.82 & 2.24 & 1.78 & 1.00 & .43 & 1.00 & .68 & 1.18 & 2.09 & .61 & 1.57 & 1.64 & 1.37 \\
\hline Fin & 73 & 1.62 & 2.02 & 1.63 & 1.05 & 1.13 & 1.15 & 1.28 & .56 & 1.55 & 1.20 & 1.41 & 1.14 & .98 \\
\hline Fra & 40 & 1.88 & 2.04 & 1.02 & 1.08 & .46 & 1.20 & 1.53 & 1.77 & 1.42 & .84 & .81 & 1.03 & .60 \\
\hline Ger & 44 & 2.43 & 2.78 & 1.95 & 1.07 & 1.09 & 1.84 & .90 & 1.42 & 1.51 & .86 & 1.86 & 1.55 & 1.14 \\
\hline $\mathrm{Gr}$ & .02 & 1.48 & 2.01 & 1.16 & 1.18 & .67 & 1.20 & 1.37 & 1.09 & 1.68 & .66 & 2.00 & 1.51 & 1.24 \\
\hline $\mathrm{Hu}$ & 82 & 1.27 & 1.98 & .71 & .83 & .40 & 1.22 & .88 & .69 & .93 & .44 & .71 & 1.01 & .87 \\
\hline Ire & 19 & 2.19 & 2.43 & 1.61 & 1.63 & 1.00 & 1.87 & 1.54 & .72 & 1.31 & .64 & 2.08 & 2.04 & 1.56 \\
\hline Ita & 1.83 & 1.77 & 1.93 & .96 & 1.30 & .72 & 1.30 & 1.60 & 1.56 & 1.58 & .89 & 1.17 & .70 & 1.20 \\
\hline Lit & 1.81 & 1.24 & 1.84 & .93 & .88 & .90 & 1.32 & 1.20 & .73 & 1.05 & .14 & 1.04 & 1.56 & 1.48 \\
\hline Neth & 1.90 & 1.73 & 2.02 & 1.58 & 1.40 & .70 & 1.40 & .74 & 1.22 & 1.11 & .74 & 2.28 & 1.85 & 1.41 \\
\hline Slok & & 1.42 & 1.65 & .77 & .78 & .50 & .41 & .76 & .31 & .89 & .54 & 1.14 & .92 & .64 \\
\hline Slov & & 2.22 & 2.72 & 1.68 & 1.57 & 1.27 & 1.67 & 1.86 & 1.95 & 1.91 & 1.29 & 1.73 & 2.48 & 1.69 \\
\hline Swe & & & & 1.54 & .96 & .34 & 1.10 & .85 & 1.59 & 1.04 & .44 & 1.48 & 1.30 & .69 \\
\hline UK & 1.84 & 1.79 & 2.10 & 1.41 & 1.28 & .62 & 1.39 & .72 & .74 & .79 & .73 & 1.63 & 1.58 & 1.30 \\
\hline Is1 & 2.21 & 2.12 & 2.11 & 1.70 & 1.38 & .41 & .84 & .94 & .99 & 1.25 & .47 & .85 & 1.27 & 1.14 \\
\hline Nor & 1.57 & 1.80 & 2.19 & 1.74 & 1.07 & .27 & .66 & .72 & .45 & 1.06 & .66 & 1.07 & 1.11 & 1.14 \\
\hline Rus & 1.30 & 1.02 & 1.50 & 1.88 & .89 & .63 & .82 & .72 & .83 & 1.19 & .93 & .70 & 1.63 & .86 \\
\hline Ser & & & & 1.39 & .71 & .43 & .29 & .78 & .39 & .51 & .37 & .57 & 1.38 & .94 \\
\hline Switz & 2.16 & 2.22 & 2.54 & 1.53 & 1.36 & 1.32 & 1.83 & 1.09 & 1.65 & 1.50 & .67 & 1.52 & 1.09 & 1.12 \\
\hline Total & 1.83 & 1.72 & 2.08 & 1.36 & 1.08 & .70 & 1.20 & 1.00 & 1.04 & 1.29 & .68 & 1.48 & 1.36 & 1.06 \\
\hline
\end{tabular}

Source: Authors research on the basis of CRANET data 
From Table 2 is evident that the most of the methods for the evaluation of career development are used to a lesser extent in all the countries that were taken for observation. The lowest average is detected for a temporary transfer to other external organizations (only 0.68) and the career development center (0.70). Moreover, among the techniques that are used in very low extent are rotation (1.00), the "high flier" scheme (1.04) and e-learning (1.06), although the internet and information technology are recognized as the trends that increase work efficiency.

On the other hand, in the countries of Europe the common used technique for career development is participation in the project teams. Specifically, such teams are used in a somewhat greater extent in comparison with other techniques (2.08). The possible reason for this ranking of teams in terms of career development is that teams can be formed at any level in the organization and contribute to the improvement of work processes and innovation and thus the development of the organization as a whole. The best way of organizing teams are crossteams (cross- functional program team) where it is important to emphasize the role of individuals in teams, their performance and on this basis, the development and career advancement. This claim has a justification because the table 2 shows that the third technique for career development is the participation in cross-organizational, crossdisciplinary and cross-functional tasks (1.72). In addition to the teams in European practices of HRM there are commonly used special tasks to stimulate learning/training at work (1.83), mentoring (1.36) and networking (1.36).
When analyzing the techniques of career development it is important to pay attention to certain trends in European countries, respectively. The post-socialist countries, which have undergone a transition period, such as Bulgaria, Hungary, and Serbia, have a low level of the usage of these techniques. This is not surprising since the transition countries usually have the problem of the lack of contemporary knowledge about management and organizations, accompanied with the lack of financial resources, since many of the mentioned techniques are expensive for organizations to implement them.

However, it cannot be concluded that only the transition countries have a low level of use of techniques of career development, when countries such as Denmark and Norway are also among those that use these techniques at low level. It is interesting that Slovenia stands out as a country where techniques for career development are used at great extent. Also, the similarities are evident between the Nordic countries, Sweden, Norway and Finland. Countries that stand out in the application of these techniques, but remain at relatively low levels, are the most developed economies of Europe, Germany, Switzerland, Ireland and Belgium.

Out of the 14 methods used in evaluating the effectiveness of career development of employees in Serbia the highest frequency of use of methods for career development are for the special assignments/projects to stimulate learning and training at work (2.09), which is followed by networking (1.39) and mentoring (1.38). In most cases, Serbian organizations lag behind the European average (Figure 1).

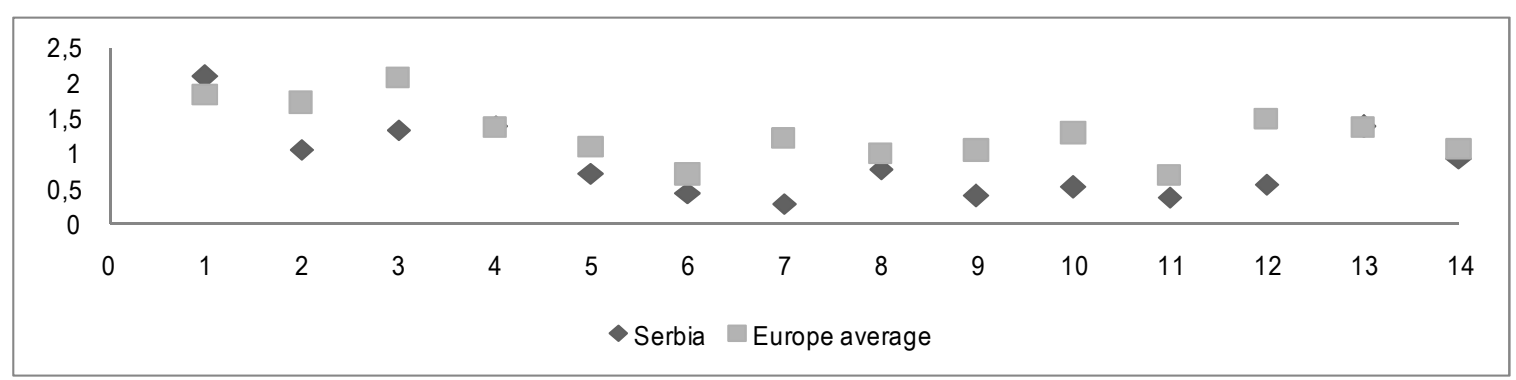

Figure 1: The level of the usage of the methods for career development-Serbian and European average ( $x$ axis presents 14 methods of career development)

Source: Authors research on the basis of CRANET data 


\section{CONCLUSION}

Career development is very important for the employees but also for organizations because it enables the development of individual's knowledge, skills and experiences, which, if is properly managed, become a source for an organization, a source of the great importance for the success in long run. Summarized knowledge, skills, attitudes and experiences of employees present the base for the growth and development of organizations. Organizations should carefully estimate the importance of their employees and manage their career development in best way to obtain all the possible advantages that will be in the function of organizational development.

In the presented study the authors found that although career development is seen as important activity of HRM, organizations from Europe use methods for career development at relatively low level. A common used technique for career development is participation in the project teams, participation in cross-organizational, crossdisciplinary and cross-functional tasks, special tasks to stimulate learning/training at work, mentoring, and networking. There are differences in international context between countries when the usages of career development methods are in question, and there is no unique pattern for this area of HRM.

\section{REFERENCES}

Baruch, J. (2004). Managing Careers: Theory and Practice. Harlow: Prentice Hall.

Baruch, Y. (2006). Career development in organizations and beyond: balancing traditional and contemporary viewpoints. Human Resource Management Review, 16(2), 125-138.

Berber, N. (2011). Human resource management in function of creating the strategic competitive advantage. Paper presented at the I International Symposium EMC 2011 June 24-25, Zrenjanin, Serbia, $93-98$.

Campbell, B. A., Coff, R., \& Kryscynski, D. (2012).
Rethinking sustained competitive advantage from human capital. Academy of Management Review, 37(3), 376-395.

Dickmann, M., \& Baruch, Y. (2011). Global careers. New York: Routledge.

Dowling, P. J., Festing, M., \& Engle, A. D. (2008). International Human Resource Management Managing people in a multinational context. London: Cengage Learning.

Grubić-Nešić, L. (2005). Razvoj ljudskih resursa ili spremnost za promene. Novi Sad: AB Print.

Heraty, N., \& Morley, M. J. (2000). Human resource development in Ireland: organizational level evidence. Journal of European Industrial Training, 24(1), 21-33.

Lado, A. A., \& Wilson, M. C. (1994). Human resource systems and sustained competitive advantage: A competency-based perspective. Academy of Management Review, 19(4), 699-727.

Leković, B., \& Šušnjar, G. (2010). Learning, education and development in comparative human resources management. Strategic Management, 15(4), 53-74.

Mayrhofer, W., Meyer, M., Iellatchitch, A., \& Schiffinger, M. (2004). Careers and human resource management-a European perspective. Human Resource Management Review, 14(4), 473-498.

Papalexandris, N., \& Panayotopoulou, L. (2004). Exploring the mutual interaction of societal culture and human resource management practices: Evidence from 19 countries. Employee Relations, 26(5), 495-509.

Parry, E., Stavrou, E., \& Lazarova, M. (2013). Global trends in human resource management. UK: Palgrave Macmillan.

Progoulaki, M., \& Theotokas, I. (2010). Human resource management and competitive advantage: An application of resource-based view in the shipping industry. Marine Policy, 34(3), 575-582.

Schuler, R. S., \& MacMillan, I. C. (1984). Gaining competitive advantage through human resource management practices. Human Resource Management, 23(3), 241-255.

Swanson, R. A. (1995). Human resource development: Performance is the key. Human Resource Development Quarterly, 6(2), 207-213.

Wright, P. M., \& McMahan, G. C. (2011). Exploring human capital: putting 'human'back into strategic human resource management. Human Resource Management Journal, 21(2), 93-104. 